\title{
Analyzing the Expression of Complementing in Harry Potter the Movie By Using Grice's Cooperative Principles: A Contextual Supplementary Material
}

\section{Ifadhotur Rizkiyah and Eriza Rezky Winanda}

Jember University, Jember, East Java

\section{Abstract}

In Indonesia, English is a foreign language which means that the language is only used for academic purposes. As the result, the students lack of English exposure outside the classroom and teacher becomes the only model of learning English. In addition, the material that the teachers use mainly textbook which the content is limited and not contextual. To overcome the problem, teachers use authentic materials to bridge the gap between the real language use and the prescriptive ones. Authentic materials

Corresponding Author: Ifadhotur Rizkiyah ifaocean@gmail.com

Received: 23 January 2019 Accepted: 26 February 2019 Published: 17 March 2019

Publishing services provided by Knowledge E

(c) Ifadhotur Rizkiyah and Eriza Rezky Winanda. This article is distributed under the terms of the Creative Commons

Attribution License, which permits unrestricted use and redistribution provided that the original author and source are credited.

Selection and Peer-review under the responsibility of the International Seminar on Language, Education, and Culture Conference Committee.

\section{G OPEN ACCESS} have some advantages such as providing various contextual and natural expressions but at the same time carries non academic language that is hard to understand. It is the teachers's job with his/her discourse competence to decipher the message for the students and uses it as the models of language expression. It is important to find different kinds of natural language models for the students in order to help them use the language naturally and appropriately. Therefore, this paper will analyze compliment and compliment response expressions in Harry Potter the movie by using Grice's Cooperative principle in order to find more examples of these expressions and to provide alternative materials in speaking class.

Keywords: implicature, authentic materials, compliments and compliment responses, pedagogical implication

\section{Introduction}

There are four kinds of communicative competence, one of them is discourse competence (Canale \& Swain, 1980). Canale \& Swain (1979) defined discourse competence as the ability of a user/learner to arrange sentences in sequence to produce coherence of a language. In this case, a language teacher also needs to acquire discourse competence in order to help them select and find appropriate materials for their students. Learning English itself cannot be separated from its culture; so, every language learner also needs to learn the culture as well when they are learning the language. Based on Tang (1999), 
culture is language and language is culture. the relationship between those two cannot be dissosiacted. He also argued that someone can speak a language well when one is able to think in that particular language. It is also supported by Brown (1994) that those two are intricately intertwined, meaning that we cannot separate the language from its culture. If so, the consequence is that we will lose the significance of either that language or its culture. Yet, according to Crystal (2003a), the status of English in Indonesia is a foreign language which means that the language is only used for academic purposes. As a result, the students lack of English exposure outside the classroom and teacher becomes the only model of learning English. Furthermore, the material that the teachers use mainly textbook which the content is limited and not contextual. It is supported by some previous findings (Syamsinar \& Baso Jabu, 2015; Yuyun Yulia, 2014). To overcome this problem, teachers should modify the materials by providing authentic materials to bridge the gap between the real language use and the prescriptive ones. Authentic materials have some advantages such as providing various contextual and natural expressions (Guariento \& Morley, 2001), but at the same time carries non academic language that has complex language structures and is hard to understand (Richard, 2001). Achieving the understanding of authenthic materials is not easy. It is the teachers's job with his/her discourse competence to elaborate the message of the language structures taken from the authentic materials for the students and uses it as the models of a language expression. Teachers who use authentic materials will more likely have an opportunity to boost students to read for pleasures especially with their topic interest (Martinez, 2002). It is important for teachers to find different kinds of natural language models for the students in order to help them use the language naturally and appropriately. Therefore, we will focus on analyzing compliment and compliment response expressions in Harry Potter the movie by using Grice's Cooperative principle in order to find more examples of these expressions which are not bookish but more likely contextualized and to provide alternative materials in speaking class.According to Holmes (1986) compliment is as a speech act which explicitly or implicitly attributes credit to someone other than the speaker. Usually, the person addressed is for some good (possession, character, skill, etc) and it is positively valued by the speaker and hearer. Meanwhile, compliment responses is regarded as a type of speech acts in which it is important to be studied. Those responses to compliments can provide different purposes of compliment (Herbert, 1989). The scenes selected from Harry Potter movie will be based on Holmes (1986) and Chung \& Chen (2010) about compliment and compliment responses. 
Cooperative principle is a principle of conversation that was proposed by Grice (1975). He argues that "conversational contribution such as is required, at the stage at which it occurs, by the accepted purpose or direction of the talk exchange." He also proposed that there are four conversational maxims which are maxim of quantity, quality, relation, and manner. Maxims seem like rules at first, but they often appear to be broken more than to be fulfilled. That is why Grice name this as 'maxims' rather than 'rules'.

\section{Methodology}

In this paper, we decided to use Harry Potter the movie entitled "Harry Potter and The Philosopher's Stone" as our data resource. The theme of the movie is about school life, and the story is suitable for students in general. According to IMDB, the story is for family and the age restriction is 7+. The English language used in the movie is British English.

The proses in conducting the data is divided into several stages. Starting from selecting the movie, selecting the scenes of compliment and compliment responses based on Holmes and Chung \& Chen, the last is analyzing the data resource using Grice's cooperative principles.

\section{Finding}

Harry Potter and The Philosopher's Stone the movie has two hours length. Within those two hours the researchers found 14 dialogues that contains the expression of complimenting, some of them are coming in an adjacency pair (Compliment-compliment response), while others are coming in a single expression (Compliment) without any verbal response. Out of 18 expressions (14 compliment and 4 compliment response) occurred in the dialogues, 10 of them (9 complimenting, 1 response) are considered in fulfilling the maxim of cooperative principle, and the other 8 (5 complimenting, 3 response) are considered to flout. The distribution of the flouting is manifested in Table 1.

Based on Table 1, it can be seen that flouting of the maxim can happen in either complimenting expression or its response. In the complimenting, out of 14 expressions, the flouting happens 5 times (35.7\%). Meanwhile, in the compliment response, out of 4 expressions, the flouting happens 3 times (75\%). That percentage is relatively higher than the compliment expression. Mostly, the characters in the movie tend to reject the compliment given to them by employing some strategies. In addition, the flouting classification is various, yet out of four maxims, only three of them appear in the movie. 
TABLE 1: The Maxim Flouting and Fulfilment Distribution.

\section{Compliment}

"I would trust Hagrid with my life"

"A wizard. And a thumping good one at that, l'd wager. Once you train up a little"

"It's a world class racing broom. Look at it, it's the new Nimbus 2000! It's the fastest model yet"

"I think it is clear that we can expect great things from you. After all, He-Who-Must-Not-Be-Named did great things...terrible, yes, but great"

“Wicked!”

"That was bloody brilliant"

"Seeker? But first years never make their house teams! You must be the youngest Quidditch player in..." "A century, according to McGonagall."

"Hey, well done, Harry, Wood's just told us!"

"Eh, not bad, Potter, you'd make a fair beater..."

"Oh, well done! See here, everyone! Ms. Granger's done it! Oh, splendid!" "As for you two gentlemen I just hope you realize how fortunate you are. Not many students could take on a full grown mountain troll and live to tell the tale. 5 points... will be awarded to each of you...for sheer dumb luck"

"That's not just any broomstick, Harry. It's a Nimbus 2000!"

"You're a great wizard, you really are."

"Not as good as you."

\section{Flouting}

Fulfilling

Total

Note: $(\checkmark)$ Fulfilling the maxim, $(x)$ Flouting the maxim

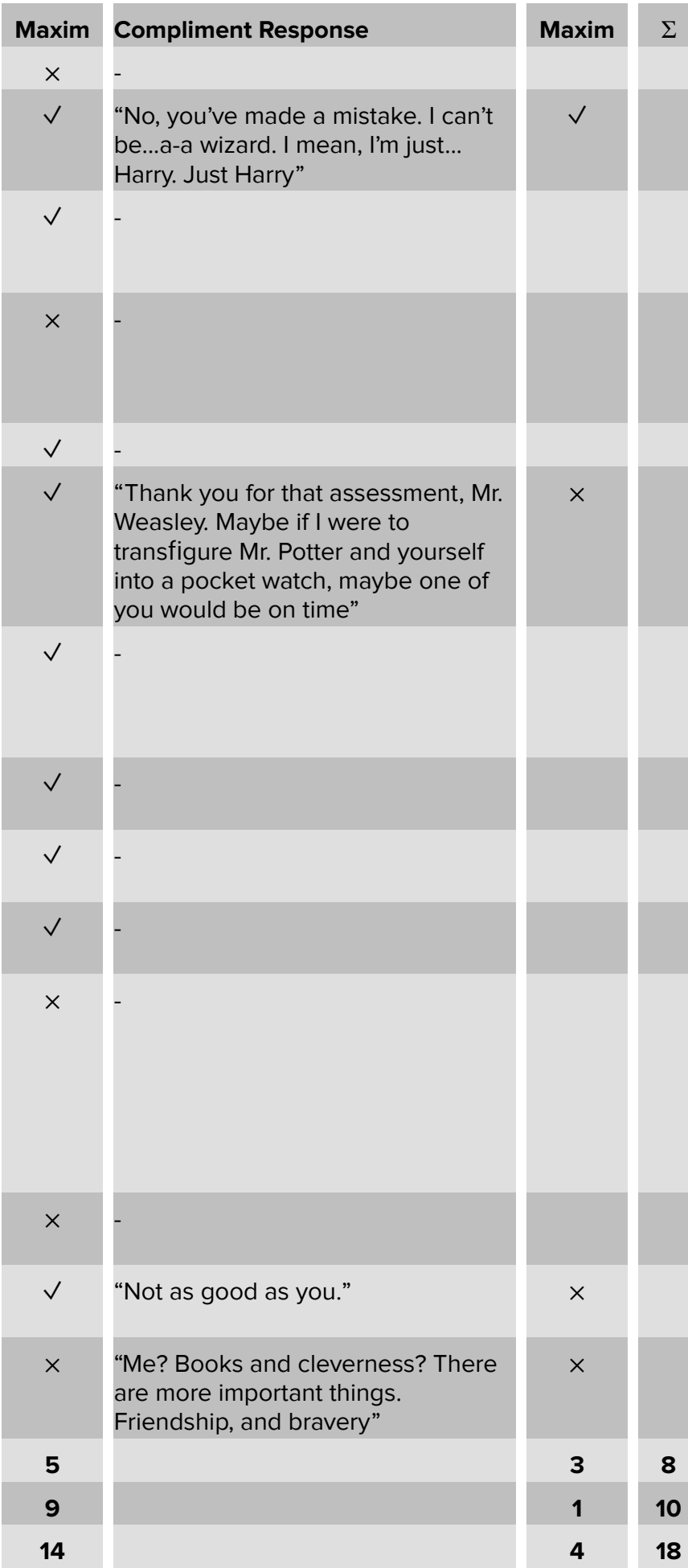

18

Those are flouting in maxim of quantity, maxim of quality, and maxim of manner. The classification of them is displayed in Table 2. 
TABLE 2: The Maxim Flouting Classification.

Expression
Compliment
Compliment response
Total
Percentage

\begin{tabular}{c} 
Quantity Maxim \\
\hline 1 \\
1 \\
2 \\
$\mathbf{2 5} \%$ \\
\hline
\end{tabular}

Manner Maxim
2
2
4
$50 \%$

From Table 2, the highest number of flouting in the movie is happening in maxim of manner. The lowest number in the compliment expression is maxim of quantity, meanwhile in the compliment response, the flouting dominantly appears in the maxim of manner. For the quality maxim, the flouting merely occurs in the compliment expression and does not seem to exist in compliment response. Here are some examples of each flouting (The complete example is available in the appendix 2).

\subsection{Maxim of quantity}

\section{Dialogue 1. 01:15:09 - 01:15:29}

Harry: It's a broomstick!

\section{Ron: That's not just any broomstick, Harry. It's a Nimbus 2000!}

Harry: But who...? (He sees Professor McGonagall up at the head table, stroking Hedwig. She smiles and Harry nods)

The conversation happened in a dining hall where Harry got a mail from the unknown. Harry, Hermione, and Ron opened it together and turned out that it was a broomstick. Upon knowing the type of the broomstick, Ron astonished and indirectly complimented it by saying 'That's not just any broomstick, Harry. It's a Nimbus 2000!'. In here, the expression uttered by Ron can be considered as flouting the quantity maxim, Ron only provided too short information and expected the hearer to understand what he meant. Through his utterance, he wanted to imply that the broomstick is a high quality one as it was Nimbus 2000 (The fastest model of broomstick at that time), yet Ron did not explain what Nimbus 2000 actually was. In addition, the utterance carries the emotive function of language since Ron showed his emotion that he was awed of the broomstick, it also brings the referential function because he give information to Harry that the broomstick is not the usual broomstick but Nimbus 2000 . 


\subsection{Maxim of quality}

\section{Dialogue 1. 00:01:53 - 00:02:06}

McGonagall: Do you think it wise to trust Hagrid with something as important as this?

Dumbledore: Ah, Professor, I would trust Hagrid with all my life.

This conversation took place at the very beginning of the movie when Professor Dumbledore and Professor McGonagall had to send baby Harry into his uncle house. Yet, Harry was still not in their hand, so Professor McGonagall asked Professor Dumbledore about him. He said that Harry was bringing him. Hearing that statement, Professor McGonagall felt in doubt and asked if it was wise to trust Hagrid dealing with that matter, yet Professor Dumbledore just said that he trusted him with all his life. From that dialogue, the answer from Dumbledore can be classified as the flouting of maxim quality. McGonagall just needed yes/no answer, but he answered her with "Ah, Professor, I will trust Hagrid with all my life". In here, Professor Dumbledore used the kind of exaggeration expression. Therefore, that expression belongs to flouting of maxim quality. Moreover, by saying such kind of answer, Dumbledore gave an indirect compliment to Hagrid which means Hagrid is a highly trustworthy person.

\subsection{Maxim of manner}

\section{Dialogue 1. 02:06:14 - 02:06:47}

Harry: Take care of Ron. Then, go to the owlery. Send a message to Dumbledore. Ron's right...I have to go on.

Hermione: You'll be okay, Harry. You're a great wizard, you really are.

Harry: Not as good as you.

Hermione: Me? Books and cleverness? There are more important things.

Friendship, and bravery. And Harry, just be careful.

The dialogue occurred when Ron was passing out after he sacrificed himself in wizard chess. Harry asked Hermione to take care of him because he needed to proceed saving the Philosopher's stone. Seeing that her friend would face something dangerous, Hermione supported him by saying a compliment that Harry is a great wizard, but Harry seemingly did not acknowledge it and went by saying 'Not as good as you are'. In this 
case, Harry flouted the maxim of manner as he was being obscure. He could have said that he was not that great, instead he complimented Hermione back by uttering not as good as you are. Moreover, the response from Hermione toward Harry's compliment can be considered the flouting of manner maxim as well. She was unclear, she thought that she was not a good wizard either because all she currently had is book and cleverness, both two things were not that important compare to friendship and bravery that Harry had. Therefore, both two characters here subtly rejected each other compliment.

\section{Discussion}

Based on the findings of this present research, it is worth mentioning that Harry Potter and The Philosopher's Stone (2001) the movie is a good source to be employed in English teaching and learning in general and teaching complimenting in particular as the content is fairly close to naturally-occurring speech. It can be seen from several areas including vocabulary choices, structure, and compliment response strategy.

For the vocabulary choices, the characters in the movie tend to use various kinds of words or expressions that commonly have negative literal meaning. For example: the word 'Wicked', according to Cambridge Dictionary, 'Wicked' literally means something which is morally wrong or bad, but in the movie, within the right and specific context, 'Wicked' is used as one of the expressions in complimenting which means something cool. There is also 'Bloody brilliant', the word 'Bloody' means covered, smeared, or running with blood, yet in a particular context it means 'Very', so 'Bloody brilliant' means very brilliant. Those kind of vocabularies also can be found in Indonesian language, such as 'Wah gila sih!'. The actual meaning of 'Gila' is a general term to describe severe mental disorder, but within a specific context, it can be used to describe something which is extremely excellent or beyond imagination. However, those type of vocabularies are rarely taught to the students, the list of complimenting expression in the English textbook commonly only covers the basic adjective such as nice, good, great, beautiful, pretty, etc. In fact, as compliment usually appears in daily conversation, which results it to be more dynamic, acknowledging various kind of contextualized vocabulary might be important. In this case, by knowing the use of those expressions, the students much or less will be equipped with the knowledge of sociolinguistic, so they can select any kind of words or expressions based on the given context and be able to use them properly in communication. Therefore, here the use of movie as the supplementary material can help them to give enough exposure of the context for a certain word or expression. 
In addition, the result shows, one of the complimenting expressions is flouting the maxim of quantity. The example is 'That's not just any broomstick, Harry. It's a Nimbus 2000 !', in this expression, any type of adjective or verb cannot be found. That thing is not in accordance with Wolfson's (1983) statement which stated that a compliment requires adjective or verb that carries someone's positive evaluation. However, the expression does not contains both, but still, having seen from the context and after being analysed with Grice's cooperative principle, the underlying intention behind it is for complimenting. Moreover, Holmes (1992) said that the function of compliment is affective and social rather than referential or informative, but the expression somehow tag along with it the referential function of language since the sentence contains information, aside from its intention for complimenting. Therefore, in this case, by employing the flouting of quantity maxim, compliment can be made even without any verb or adjective as long as the context is appropriate.

For the complimenting response strategy, there are two kinds of complimenting response strategy used by the characters in the movie: Giving back the compliment and accepting the compliment. The way they give back the compliment is commonly by flouting the maxim of manner. It might be because when the manner maxim is flouted, the speaker is unclear and ambiguous, so it can help to make the return as subtle as possible. That kind of strategy is called amendment strategy (Chung, 2010), in which the speaker tries to amend its complimentary force. The example of the strategy is when Harry responded 'Not as good as you' to Hermione's compliment and Hermione responded back with "Me? Books and cleverness? There are more important things. Friendship, and bravery". In this case, both parties reciprocate each other's compliment. In addition, the character in the movie also accept the compliment, but what make it difference is that the acceptance did not seem sincere. That happened when Professor McGonagall responded Ron's compliment with 'Thank you for that assessment, Mr. Weasley. Maybe if I were to transfigure Mr. Potter and yourself into a pocket watch, maybe one of you would be on time'. Here, Professor McGonagall employed the maxim of manner to reprimand Harry and Ron's lateness (See appendix). However, the highlight here is the use of 'Thank you' in accepting compliment. Saying 'Thank you', according to Chung (2010), is one of the examples to show an appreciation toward compliment, but in this context, the expression of 'Thank you' means the opposite. By flouting the maxim of cooperative principle, the character deliberately used 'Thank you' to mean something else. Therefore, given such an explanation, context is an important thing in interpreting someone's utterances. 
All in all, for the vocabulary, the words or the expressions uttered by the characters in their compliment is relatively various and diverse. This thing is good to be taught to the students for their supplementary material in complimenting others. As for the structure, it is somehow can be flexible based on the context given and the compliment strategy the speaker want to employ. Lastly, for the complimenting response strategy, out of three strategies suggested by Chung (2010), the characters in the movie used two of them, they are amendment strategy and acceptance strategy.

\section{Conclusion \& Suggestion}

Finally, based on those findings, it is reasonable to use movie as one of the supporting material in English teaching and learning. After all, learners do need to acquire knowledge of the culture of the target language, and movie provides a context for this to take place. Learning a language cannot be separated from its culture, and teacher as the facilitator in learning has to give the learners as much language exposure as possible to them, so that they can use language appropriately. Moreover, context plays an important role, without any context, any utterance might be interpreted improperly as a word could mean something in a certain context, yet mean another thing when the context is different. Therefore, a language teacher must teach the language in contextualized way and movie is a good media to be employed in this matter. By using the movie as the supplementary material aside from textbook, the language learners can have enough exposure of the language-use they have to pay attention to when using the language. Hence, their language will sound more natural instead of bookish.

For the suggestion, this research suggests the accompaniment of teacher in understanding the English material. In teaching compliment and compliment responses from a movie, teacher is badly needed to assist students in understanding certain words which might be bad in some context but not bad in another context. In the guidance of the teacher, it will be easier for students to select certain words which is contextual and proper. Not only assisting, teacher can also help students with deeper discussion. In this case, students will learn to use their sociolinguistic competence. This lesson of compliment and compliment responses will be best taught in 10th grade of high school based on the Kurikulum 2013. 


\section{References}

[1] Canale, M. \& Swain, M. (1979). Theoretical Bases of Communicative Approaches to Second Language Teaching and Testing," Applied Linguistics, vol. 1, no. 1, pp. 1-39,

[2] Chung, H \& Chen, S. (2010). A Study on The Effect Of Status on Compliment Response Strategies By Taiwanese EFL Young Learners And Its Pedagogical Implications. National Taipe University of Education

[3] Crystal, D. (2003a). English as a Global Language, (2nd Ed.). Cambridge: Cambridge University Press.

[4] Grice, H. P. (1975). Logic and Conversation. In Speech Acts [Syntax and Semantics 3], Peter Cole and Jerry Morgan (eds), 41-58. New York: Academic Press.

[5] Guariento, W. \& Morley, J. (2001).Text and task authenticity in the EFL classroom. ELT Journal 55(4), 347-353

[6] Herbert, R. K. (1989). The structure of English compliment and compliment responses: A contrastive sketch. In W. Olesky (eds.), contrastive pragmatics. Amesterdam: John Benjamins. 3.35

[7] Holmes, J. (1986). Compliments and compliment responses in New Zealand English. Anthropologicallinguistics

[8] Holmes, J. and Brown P. (1987). Teachers and students learning about compliments. TESOL Quarterly, 523-546. http://dx.doi.org/10.2307/3586501

[9] Holmes, J. (1992). An Introduction to Sociolinguistics. London: Longman

[10] Martinez, A. (2002). Authentic materials: An overview. Karen's Linguistic Issues.Retrieved on July 20, 2018 from http://www3.telus.net/linguisticsissues/ authenticmaterials.html

[11] Richard, J.C. (2001). Curriculum development in language teaching. Cambridge: Cambridge University Press.

[12] Romana, T. (1999). The place of 'culture' in the Foreign Language Classroom: A Reflection.

[13] Wolfson, N. (1983). An empirically based analysis of complimenting in American English. In N. Wolson \& E.Judd (Eds.) Sociolinguistics and language acquisition (pp. 90). Rowley, Mass: Newbury House.

\section{Appendix}




\title{
Appendix 1. The list of compliment and compliment response excerpt in the movie
}

TABLE 3

\begin{tabular}{|c|c|c|}
\hline No. & Minute & Excerpt \\
\hline 1. & 00:01:43 - 00:02:06 & Dumbledore: "I would trust Hagrid with my life" \\
\hline 2. & $00: 15: 11-00: 15: 27$ & $\begin{array}{l}\text { Hagrid: "A wizard. And a thumping good one at that, l'd wager. } \\
\text { Once you train up a little" Harry: "No, you've made a mistake. I } \\
\text { can't be...a-a wizard. I mean, I'm just... Harry. Just Harry" }\end{array}$ \\
\hline 3 & $00: 21: 25-00: 21: 41$ & $\begin{array}{l}\text { A boy: "It's a world class racing broom. Look at it, it's the new } \\
\text { Nimbus } 2000 \text { ! It's the fastest model yet" }\end{array}$ \\
\hline 4. & $00: 27: 20-00: 28: 35$ & $\begin{array}{l}\text { Ollivander: "I think it is clear that we can expect great things } \\
\text { from you. After all, He-Who-Must-Not-Be-Named did great } \\
\text { things...terrible, yes, but great" }\end{array}$ \\
\hline 5. & $00: 34: 32-00: 34: 54$ & Ron: “Wicked!” \\
\hline 6. & $00: 50: 55-00: 51: 12$ & $\begin{array}{l}\text { Ron: "That was bloody brilliant" McGonagall: "Thank you for that } \\
\text { assessment, Mr. Weasley. Maybe if I were to transfigure Mr. } \\
\text { Potter and yourself into a pocket watch, maybe one of you would } \\
\text { be on time" }\end{array}$ \\
\hline 7. & $00: 59: 56-01: 00: 05$ & $\begin{array}{l}\text { Ron: "Seeker? But first years never make their house teams! You } \\
\text { must be the youngest Quidditch player in..." Harry: "A century, } \\
\text { according to McGonagall." }\end{array}$ \\
\hline 8. & 01:00:05 - 01:00:08 & Fred: “Hey, well done, Harry, Wood's just told us!” \\
\hline 9. & $01: 04: 29-01: 04: 52$ & Oliver: “Eh, not bad, Potter, you'd make a fair beater...” \\
\hline 10. & 01:06:55 - 01:07:14 & $\begin{array}{l}\text { Flitwick: "Oh, well done! See here, everyone! Ms. Granger's done } \\
\text { it! Oh, splendid!" }\end{array}$ \\
\hline 11. & 01:13:59 - 01:14:13 & $\begin{array}{l}\text { McGonagall: "As for you two gentlemen I just hope you realize } \\
\text { how fortunate you are. Not many students could take on a full } \\
\text { grown mountain troll and live to tell the tale. } 5 \text { points... will be } \\
\text { awarded to each of you...for sheer dumb luck" }\end{array}$ \\
\hline 12. & 01:59:09 - 01:15:29 & Ron: "That's not just any broomstick, Harry. It's a Nimbus 2000!" \\
\hline 13. & $02: 06: 12-02: 06: 33$ & $\begin{array}{l}\text { Hermione: "You're a great wizard, you really are." Harry: "Not as } \\
\text { good as you." }\end{array}$ \\
\hline 14. & $02: 06: 33-02: 06: 47$ & $\begin{array}{l}\text { Harry: "Not as good as you." Hermione: "Me? Books and } \\
\text { cleverness? There are more important things. Friendship, and } \\
\text { bravery" }\end{array}$ \\
\hline
\end{tabular}

\section{Appendix 2. The explanation of the maxim flouting}

\author{
Maxim of Quantity Flouting
}

Dialogue 1. 00:50:55 - 00:51:12

Ron: That was bloody brilliant. 


\section{McGonagall: Thank you for that assessment, Mr. Weasley. Maybe if I were to transfigure Mr. Potter and yourself into a pocket watch, maybe one of you would be on time.}

The dialogue happened when Harry and Ron was coming late into transfiguration class. At first, they thought that they were save since their teacher, Professor McGonagall, had not come to class, but it turned out that the cat on the teacher's table was actually her who transfigured herself as a cat, both Harry and Ron got red handed. Yet, as seeing his teacher transformed from a cat into a human, Ron amazed and automatically uttered a compliment toward her, McGonagall halfheartedly accept his compliment by saying thank you, but her utterances did not end that way. She continued saying that if she could transform Harry and Ron into a pocket watch, they might be on time. In this case, the McGonagall's response of Ron's compliment is considered as flouting the quantity maxim, just like what Grice said, if someone flout the maxim of quantity, he will give too less or too much information. Here, McGonagall actually could have only said 'Thank you for your assessment Mr. Weasley', but she continued saying thing as she did not like Harry and Ron being late to her class. Even though at first, McGonagall said thank you to Ron's compliment, the continuation screamed otherwise.

\section{Dialogue 2. 01:59:09 - 01:15:29}

Harry: It's a broomstick!

\section{Ron: That's not just any broomstick, Harry. It's a Nimbus 2000!}

Harry: But who...? (He sees Professor McGonagall up at the head table, stroking Hedwig. She smiles and Harry nods)

The conversation happened in a dining hall where Harry got a mail from the unknown. Harry, Hermione, and Ron opened it together and turned out that it was a broomstick. Upon knowing the type of the broomstick, Ron astonished and indirectly complimented it by saying 'That's not just any broomstick, Harry. It's a Nimbus 2000!'. In here, the expression uttered by Ron can be considered as flouting the quantity maxim, Ron only provided too short information and expected the hearer to understand what he meant. Through his utterance, he wanted to imply that the broomstick is a high quality one as it was Nimbus 2000 (The fastest model of broomstick at that time), yet Ron did not explain what Nimbus 2000 actually was. In addition, the utterance carries the emotive function of language since Ron showed his emotion that he was awed of the broomstick, it also 
brings the referential function because he give information to Harry that the broomstick is not the usual broomstick but Nimbus 2000.

\section{Maxim of Quality Flouting}

\section{Dialogue 1. 00:01:43 - 00:02:06}

McGonagall: Do you think it wise to trust Hagrid with something as important as this?

Dumbledore: Ah, Professor, I would trust Hagrid with all my life.

This conversation took place at the very beginning of the movie when Professor Dumbledore and Professor McGonagall had to send baby Harry into his uncle house. Yet, Harry was still not in their hand, so Professor McGonagall asked Professor Dumbledore about him. He said that Harry was bringing him. Hearing that statement, Professor McGonagall felt in doubt and asked if it was wise to trust Hagrid dealing with that matter, yet Professor Dumbledore just said that he trusted him with all his life. From that dialogue, the answer from Dumbledore can be classified as the flouting of maxim quality. McGonagall just needed yes/no answer, but he answered her with "Ah, Professor, I will trust Hagrid with all my life". In here, Professor Dumbledore used the kind of exaggeration expression. Therefore, that expression belongs to flouting of maxim quality. Moreover, by saying such kind of answer, Dumbledore gave an indirect compliment to Hagrid which means Hagrid is a highly trustworthy person.

\section{Dialogue 2. 01:13:59 - 01:14:13}

Hermione: I went looking for the troll. I'd read about them and thought I could handle it. But I was wrong. If Harry and Ron hadn't come and found me...l'd probably be dead.

McGonagall: Be that as it may...it was an extremely foolish thing to do. I would have expected more rational behavior on your part, Ms. Granger. 5 points will be taken from Gryffindor for your serious lack of judgment. As for you two gentlemen I just hope you realize how fortunate you are. Not many students could take on a full grown mountain troll and live to tell the tale. 5 points...will be awarded to each of you. For sheer dumb luck. 
The conversation occurred in the girls' toilet where Harry and Ron saved Hermione from a troll. Suddenly some teachers including McGonagall came and surprised as seeing the trio in the bathroom instead of their dormitory. She was ready to scold them, yet Hermione stepped forward and said that everything was her fault not the other two boys, she mentioned that if Harry and Ron did not come, she might be in danger because of the troll. Upon hearing Hermione's explanation, McGonagall took five points from Gryffindor house for the compensation of her behavior and warned her not to do such a foolish thing again. She also warned Harry and Ron, but behind her warning, there is an indirect compliment in it. She said 'Not many students could take on a full grown mountain troll and live to tell the tale', this utterance explains that McGonagall indirectly wanted to say that what Ron and Harry did was considered to be a big deal since it was not something that the first year could do. Hence, she awarded 5 points for each of them. However, her expression can be classified into the flouting of quality maxim since it contains sarcasm in it. McGonagall wanted to imply that Even though defeating the troll is a great thing for the first year, but still it was dangerous, Ron and Harry might hurt or worse if the luck was not by their side. Therefore, the utterance not only contains indirect compliment but also warning.

\section{Maxim of Manner Flouting}

\section{Dialogue 1. 00:27:20 - 00:28:35}

Harry: And...who owned that wand?

Ollivander: Oh, we do not speak his name. The wand chooses the wizard, Mr. Potter. It's not always clear why, but I think it is clear that we can expect great things from you. After all, He-Who-Must-Not-Be-Named did great things...terrible, yes, but great.

The conversation took place when Harry bought his wand to Ollivander. The wand turned out to be the same type of wand that Voldemort had back then when he was also the first year of Hogwards. Ollivander felt curious and consciously complimented Voldemort (He-Who-Must-Not-Be-Named) that back then, he did many terrible things but great. However, the utterance belongs to the flouting of manner maxim since Ollivander was being ambiguous. Grice said that when people flout the maxim of manner, they will be ambiguous and unclear. Here, it seems that Ollivander thought that Harry might be a great wizard too as his wand is the same with Voldemort. Yet, he did not say it directly, instead he was being ambiguous by saying "I think it is clear that we can expect great 
things from you. After all, He-Who-Must-Not-Be-Named did great things...terrible, yes, but great'. The reason why he did that might be because he wanted to accommodate Harry, so the boy would not be overwhelmed. After all, Voldemort was the one who killed his parent, hence having the similarity with him probably was terrifying.

\section{Dialogue 2. 02:06:12 - 02:06:47}

Harry: Take care of Ron. Then, go to the owlery. Send a message to Dumbledore. Ron's right...I have to go on.

Hermione: You'll be okay, Harry. You're a great wizard, you really are.

Harry: Not as good as you.

Hermione: Me? Books and cleverness? There are more important things.

Friendship, and bravery. And Harry, just be careful.

The dialogue occurred when Ron was passing out after he sacrificed himself in wizard chess. Harry asked Hermione to take care of him because he needed to proceed saving the Philosopher's stone. Seeing that her friend would face something dangerous, Hermione supported him by saying a compliment that Harry is a great wizard, but Harry seemingly did not acknowledge it and went by saying 'Not as good as you are'. In this case, Harry flouted the maxim of manner as he was being obscure. He could have said that he was not that great, instead he complimented Hermione back by uttering not as good as you are. Moreover, the response from Hermione toward Harry's compliment can be considered the flouting of manner maxim as well. She was unclear, she thought that she was not a good wizard either because all she currently had is book and cleverness, both two things were not that important compare to friendship and bravery that Harry had. Therefore, both two characters here subtly gave back each other compliment. 